\title{
DNA Methylation in the Adipose Tissue and Whole Blood of Agent Orange-exposed Operation Ranch Hand Veterans
}

Matthew Rae Rytel ( $\square$ matthew_rytel@alumni.brown.edu )

Brown University School of Public Health https://orcid.org/0000-0002-8316-1576

Rondi Butler

Brown University School of Public Health

Melissa Eliot

Brown University School of Public Health

Joseph M. Braun

Brown University School of Public Health

E. Andres Houseman

Statistical Bioinformatics, GlaxoSmithKline

Karl T. Kelsey

Brown University School of Public Health

\section{Research}

Keywords: Adipose, blood, dioxin, Agent Orange, DNA methylation, epigenetics

Posted Date: November 2nd, 2020

DOI: https://doi.org/10.21203/rs.3.rs-99596/v1

License: (c) (i) This work is licensed under a Creative Commons Attribution 4.0 International License.

Read Full License

Version of Record: A version of this preprint was published at Environmental Health on April 13th, 2021.

See the published version at https://doi.org/10.1186/s12940-021-00717-y. 


\section{Abstract}

\section{Background}

Between 1962 and 1971, the US Air Force sprayed Agent Orange across Vietnam, exposing many soldiers to this dioxin-containing herbicide. Several negative health outcomes have been linked to Agent Orange exposure, but data is lacking on the effects this chemical has on the genome. Therefore, we sought to characterize the impact of Agent Orange exposure on DNA methylation in the whole blood and adipose tissue of veterans enrolled in the Air Force Health Study (AFHS).

\section{Methods}

We received adipose tissue $(n=37)$ and whole blood $(n=42)$ from veterans in the AFHS. Study participants were grouped as having low, moderate, or high TCDD body burden based on their previously measured serum levels of dioxin. DNA methylation was assessed using the Illumina $450 \mathrm{~K}$ platform.

Results

Epigenome-wide analysis indicated that there were no FDR-significantly methylated CpGs in either tissue with TCDD burden. However, 3 CpGs in the adipose tissue (contained within SLC9A3, LYNX1, and TNRC18) were marginally significantly $(q<0.1)$ hypomethylated, and $1 \mathrm{CpG}$ in whole blood (contained within PTPRN2) was marginally significantly $(q<0.1)$ hypermethylated with high TCDD burden. Analysis for differentially methylated DNA regions yielded $S L C 9 A 3$, among other regions in adipose tissue, to be significantly differentially methylated with higher TCDD burden. Comparing whole blood data to a study of dioxin exposed adults from Alabama identified a CpG within the gene SMO that was hypomethylated with dioxin exposure in both studies.

\section{Conclusion}

We found limited evidence of dioxin associated DNA methylation in adipose tissue and whole blood in this pilot study of Vietnam War veterans. Nevertheless, loci in the genes of SLC9A3 in adipose tissue, and PTPRN2 and SMO in whole blood, should be included in future exposure analyses.

\section{Background}

Operation Ranch Hand (1962-1971) was a mission conducted by the US military during the War in Vietnam in which the Air Force dispersed millions of gallons of herbicides across Vietnam to destroy vegetative cover and crops that benefitted enemy forces [1]. The most widely used herbicide was Agent Orange, and the soldiers assigned to Operation Ranch Hand were exposed to it during mixing, loading, spraying, and clean-up duties [1]. The defoliant was contaminated with 2,3,7,8-tetrachlorodibenzo- $p$ dioxin (TCDD), which was a byproduct of the manufacturing process. TCDD is lipophilic and bioaccumulates, persisting in the human body with a half-life of 7 to 11 years [1]. TCDD is highly toxic 
and has been shown to disrupt endocrine signaling, trigger oxidative stress, and alter the epigenome [2], [3].

Shortly after the end of Operation Ranch Hand, the veterans reported health issues that they believed were related to their Agent Orange exposure [4]. This prompted the Air Force to launch a prospective, longitudinal study in 1982 termed the Air Force Health Study (AFHS), which was designed to track morbidity of the Ranch Hand veterans [4]. Using data from the AFHS, studies have tied a variety of conditions to Agent Orange exposure. The National Academies of Sciences has concluded that there is "sufficient evidence of an association" of Agent Orange exposure with soft-tissue sarcoma, non-Hodgkin lymphoma, chronic lymphocytic leukemia, Hodgkin lymphoma, chloracne, hypertension, and monoclonal gammopathy of undetermined significance [1]. However, the impact of Agent Orange exposure on the epigenome of the Ranch Hand veterans "remains uncertain" [1]. Therefore, targeting our analysis on methylation in the DNA of adipose and whole blood tissue samples collected as part of the AFHS, we sought to characterize the effect of TCDD exposure on the epigenome of the Ranch Hand veterans.

Adipose tissue plays a key regulatory role in fatty acid and cholesterol metabolism, which when dysregulated, can contribute to cardiovascular disease [5], [6]. Also, adipose tissue has a range of endocrine functions that influence multiple processes including insulin signaling, appetite, blood pressure, and immune function [5], [6]. TCDD has previously been shown to both augment and inhibit lipid accumulation in adipocytes [7]-[11]. Further, murine adipocyte differentiation was inhibited by TCDD exposure in vitro, and this change was accompanied by global demethylation [12]. TCDD also hampers insulin-mediated glucose uptake in 3T3-L1 adipocytes, possibly linking exposure to type II diabetes [13]. Gene expression analyses in human adipocytes and preadipocytes provide evidence that TCDD impacts metabolic pathways, and also upregulates genes related to the inflammatory immune response and cancer [14]. Taken together, gene expression and regulation in adipose tissue has a variety of impacts on health, and these processes clearly could be influenced by exposure to TCDD.

Methylation in whole blood has been examined as a biomarker for a variety of pathologies including cancer, metabolic disorders, and cardiovascular disease (reviewed in [15]). Observing changes in methylation in the whole blood of adults living in Anniston, Alabama who were exposed to the organochlorine class termed polychlorinated biphenyls (PCBs), including TCDD, Pittman et al. found 28 CpGs and 115 differentially methylated regions (DMRs) to be significantly aberrantly methylated with elevated serum levels of PCBs [16]. In a subsequent follow-up of the same study, $116 \mathrm{CpGs}$ were significantly associated with PCB burden at the 5\% FDR level [17]. Studies on these Anniston adults have drawn associations between PCB exposure and hypertension, liver disease, metabolic syndrome, elevated serum lipid levels, and diabetes [16]- effects thought to be associated with exposure to these chemicals. Alterations to the epigenome of whole blood in adults has been observed in other instances of exposure to persistent polychlorinated organic pollutants, as well [18]-[21]. Here, we conducted a pilot EWAS of both peripheral blood and adipose tissue, examining the association of DNA methylation changes in these tissues with measured TCDD levels in Ranch Hand AFHS participants. 


\section{Methods}

Potential participants of the AFHS were identified via an in-depth search of all organizational records stored at the Military Records Division, National Personnel Records Center, St. Louis, Missouri [22]. All Ranch Hand veterans were targeted as the study population and $99.5 \%$ were located [23]. Contacted Ranch Hand veterans and control participants were fully informed of the nature and purpose of the medical examinations and tests and signed an informed consent form before enrolling in the AFHS [22]. Consenting Operation Ranch Hand veterans and their matched controls underwent physical examinations at time points 1, 3, 5, 10, 15, and 20 years after the initiation of the Air Force Health Study in 1982 [24]. The control participants were a similar group of soldiers who flew cargo aircraft elsewhere in Southeast Asia between 1962 and 1971 and were not exposed to Agent Orange or other herbicides [24]. The Center for Disease Control and Prevention completed additional blood draws in 777 Ranch Hand veterans and 1,174 control participants at 5,10 , and 15 years after the initiation of the AFHS and measured serum TCDD levels [24]. To study methylation features associated with dioxin exposure, we stratified participants by lipid-adjusted serum dioxin (TCDD) levels into four TCDD burden groups: control, low, moderate, and high.

Whole venous blood samples were collected from Ranch Hand and control veterans in cycles 1 (1982) and 6 (2002) respectively [25]. Adipose tissue samples were extracted from a subset of participants in cycle 5 (1997) [24], [25]. The protocol used to isolate and process whole blood samples was described in the Vietnam Experience Study [26]. Adipose tissue collection and processing methods were also described in the Science Applications International Corporation test plans for sample collection [25], [27].

We received whole blood and adipose samples and isolated genomic DNA. Briefly, we digested 6.5$45.4 \mathrm{mg}$ of adipose tissue in Qiagen Buffer ATL and proteinase $\mathrm{K}$ at $56^{\circ} \mathrm{C}$ for 2 hours with agitation (300 rpm in an Eppendorf Thermomixer; occasional gentle vortexing to disrupt tissue). Then, we treated DNA with $150 \mathrm{U} / \mathrm{ml}$ RNase $A$ for 10 minutes at room temperature and subsequently recovered it using the Zymo Clean \& Concentrator-5 kit as directed. Employing the Qiagen QIAmp DNA Blood Mini Kit per manufacturer instructions, we extracted whole blood DNA. We bisulfite converted all DNA samples using the Zymo EZ DNA Methylation kit and applied the alternative incubation conditions for Illumina Infinium Methylation Array samples. We sent samples to the UCSF Genomics Core Facility, Institute for Human Genetics, for array processing.

We used the Illumina 450K Infinium Methylation platform to measure global DNA methylation levels in the Ranch Hand veteran and control groups. Processed and normalized data met all quality control standards. On the Infinium 450K platform, DNA methylation is typically measured on a "beta" scale, representing the fraction of methylated molecules (for each target site), bounded by 0 (unmethylated) and 1 (methylated).

We completed all statistical analyses using R statistical software [28]. Upon obtaining average beta values from the Infinium $450 \mathrm{~K}$ array we normalized the data and executed quality assurance and quality control measures. This included removal of poor quality $\mathrm{CpGs}$ and samples on the basis of detection $p$ - 
value [29], discovery and removal of cross reactive CpGs [30], and the removal of CpGs containing polymorphic sites with a minor allele frequency $>1 \%$ at the target site or within the probe sequence. We corrected technical variation in specimen sequencing associated with non-specific fluorescence using the Noob method [31] of the Bioconductor package minfi. Next, we utilized the FunNorm procedure [32] for functional normalization to correct for between-array variance associated with control probes. Employing the BMIQ technique [33], we then corrected for variance associated with the two different probe designs present in the array. Finally, we adjusted for batch effects using the ComBat method [34]. After these steps, the original number of CpGs was lowered from 485,577 to 485,283 loci for adipose tissue, and to 485,211 for whole blood.

We used an epigenome wide association study (EWAS) to investigate the relationship between dioxin burden and methylation at individual $\mathrm{CpG}$ loci across the entire adipose tissue genome. We examined potential confounding variables using AFHS participant data including smoking history, body mass index (BMI), and age. To estimate the number of additional confounders, we conducted a surrogate variable analysis (SVA) [35] with the Bioconductor SVA package, finding five surrogate variables. Next, we employed linear models with empirical Bayes estimation to test for a possible association between dioxin levels and differential methylation. We included smoking history (ever or never), BMI ( $\mathrm{kg} / \mathrm{m}^{2}$ ), age (years), and the surrogate variables in the model as covariates. We modeled dioxin level as a categorical variable (e.g., control vs. high). Finally, we used the Benjamini-Hochberg $(\mathrm{BH})$ method to control the false discovery rate (FDR). We ordered $\mathrm{CpG}$ s by $\mathrm{BH}$-adjusted $p$-values in an increasing fashion to identify significantly differentially methylated loci.

We also examined regional changes in DNA methylation applying the DMRcate package (Bioconductor), which has been shown to outperform other tools used to study differentially methylated regions of DNA [36]. Excluding CpGs located within SNPs, DMRcate identified changes in beta values for each of the 46,470 regions in the control and high serum TCDD groups. We measured significance using the Stouffer $p$-value (regional level), and the minimum adjusted $p$-value from the $\mathrm{CpGs}$ within the regions. Regions were ordered according to the minimum adjusted $p$-value to identify DMRs potentially differentially methylated in the high burden group compared to the control.

We proceeded to analyze the whole blood data, executing an EWAS that used SVA to account for white blood cell composition and any additional confounders. To compare methylation levels in the control versus high burden groups, we built linear models with empirical Bayes estimation that adjusted for age (years), BMI $\left(\mathrm{kg} / \mathrm{m}^{2}\right)$, smoking history (ever vs. never), and the 8 surrogate variables identified using SVA. Again, we employed BH-method to control the FDR. Following this EWAS using SVA, we deconvoluted the blood data to obtain estimates of the proportions of the different leukocytes in the sample. The neutrophil to lymphocyte and lymphocyte to monocyte ratios (NLR and LMR respectively) were calculated for each participant. Subsequently, we carried out additional genome-wide scans comparing methylation betas in the control and high dioxin load groups, this time adjusting for the demographic data and the blood cell proportions or the demographic data and the NLR. After employing the $\mathrm{BH}$ method to control the FDR, we ordered CpGs according to their adjusted $p$-value in order to identify significantly 
differentially methylated loci. In line with our procedures from the previous sample types, we applied DMRcate to identify regions of differentially methylated DNA with elevated serum TCDD levels.

Abnormal leukocyte proportions, and in particular, the NLR and the LMR are indices of systemic inflammation and can serve as predictors for diseases like cancer [37], [38]. We used t-tests to compare cell type proportions, the NLR, and the LMR between the highly exposed group and the control group.

Using data from the Anniston Community Health Survey (ACHS) II [17] we performed a candidate-CpG analysis with the whole blood data. We identified the 116 significantly methylated $\mathrm{CpG}$ loci with dioxin exposure at the 5\% FDR level in the AFHS data [17], and subsequently, performed t-tests comparing methylation levels in the high burden group compared to the controls. Another study targeted CYP1A1 and IGF2 in a candidate-gene analysis of the whole blood of Vietnamese individuals potentially exposed to Agent Orange [39]. At each of the CpGs within CYP1A1 and IGF2 in the AFHS whole blood 450K data, we executed a t-test to compare methylation levels between the highly burdened group and the controls. Finally, we performed a candidate analysis using the same approach in both the adipose tissue and whole blood data for genes within the AHR pathway (AHR, AHRR, CYP1A1, CYP1A2, CYP1B1, and ARNT).

We next used the Hannum, Horvath, and phenoAge epigenetic clock analyses to estimate the chronological ages of the Ranch Hand veterans and controls in whole blood. The Hannum clock is based on the methylation profile at $71 \mathrm{CpGs}$ and was constructed using, and tested on, whole blood data [40], [41]. This clock also takes into account age-related shifts in blood cell proportions [40], [41]. In contrast, the Horvath clock was built using methylation data from multiple tissues, and includes a set of $353 \mathrm{CpGs}$ [41], [42]. PhenoAge consists of a set of $513 \mathrm{CpGs}$, and was trained using whole blood methylation data and on chronological age as well as aging- and lifestyle-related disease phenotypes [43]. PhenoAge has been shown to perform with high precision in tissues other than whole blood [43]. We also estimated chronological age using the adipose tissue data. However, due to the fact that the Hannum clock is best suited for use with whole blood data, we did not apply this method to the adipose tissue data.

We completed the Hannum and Horvath clock analyses through the wateRmelon package; the PhenoAge clock was accessed through the ENmix package. For each participant, we calculated age acceleration by regressing methylation age on chronological age and taking the residuals from the model [44]. We examined possible associations between age acceleration and dioxin burden using linear models. In this analysis, we modeled serum dioxin levels both as categorical and continuous variables. For analysis with the whole blood data, we constructed five different models, which accounted for covariates that could impact methylation age estimates, to assess the relationship between age acceleration and DNA methylation: adjusting for cell type proportions (model 1), NLR (model 2), BMI, and smoking history (model 3), cell type proportions, BMI, and smoking history (model 4), and NLR, BMI, and smoking history (model 5). Only model 3 was applied to the adipose tissue data. The cell type proportions used were the estimates generated from the deconvolution analysis.

\section{Results}


In the adipose tissue data, we stratified participants (exposed and control veterans) based on lipidadjusted serum dioxin levels (LSDL) into four burden groups: control (LSDL ranging from 2.21 to 7.05 $\mathrm{ppt} ; n=12$ ), low (LSDL ranging from 5.6 to $7.24 \mathrm{ppt} ; n=3$ ), moderate (LSDL between 8.9 and $19.6 \mathrm{ppt} ; n=$ 11 ), and high (LSDL ranging from 26.6 to $167.6 \mathrm{ppt} ; n=11$ ) (Table 1). We grouped participants in the same manner in the whole blood data: control (LSDL ranging from 2.21 to $7.05 \mathrm{ppt} ; n=11$ ), low (LSDL ranging from 5.6 to $7.24 \mathrm{ppt} ; n=4$ ), moderate (LSDL between 8.9 and $19.6 \mathrm{ppt} ; n=11$ ), and high (LSDL between 26.6 and $167.6 \mathrm{ppt} ; n=15)$. There were no participants with non-detectable dioxin levels in either tissue group. Serum dioxin concentration was the only variable that significantly differed between the control and high TCDD burden groups.

We began epigenomic analysis of the adipose tissue DNA with an EWAS to determine if any individual loci were aberrantly methylated to a level of genome-wide significance in the highly burdened Ranch Hands compared with the control veterans. We found 35,216 CpGs to be significantly differentially methylated in the high dioxin load group compared to the control $(p<0.05)$; however, no CpGs survived correction for multiple comparisons at any loci. Three CpGs (cg18447419, cg04350571, and cg04939944) showed marginal genome-wide significant methylation ( $\mathrm{q}<=0.1)$ (Table 2). These marginally significant loci were all hypomethylated and were associated with the genes SLC9A3, LYNX1, and TNRC18. Additionally, LOC14937 contained two of the 50 most significantly altered CpGs by $q$-value, and in each case, the locus was hypomethylated as indicated by the associated regression coefficient (Table 2). Similarly, STAB1 contained two of the CpGs within the 50 lowest $q$-value group, and in each case the loci were hypermethylated (Table 2). Furthermore, since dioxin is known to interact with genes in the AHR pathway, members of this pathway were examined for TCDD serum associated methylation alterations, but no statistically significant relationships were found (data not shown).

After adjusting for multiple testing, none of the 46,470 DMRs studied were altered to reach a significant Stouffer $p$-value in the adipose tissue data. However, comparing the high to control burden groups, 11 of the regions resulted in a minimum adjusted $p$-value $<10^{-6}$ based on methylation at the CpGs contained within the regions (Table 3). Many of these DMRs contain genes associated with non-coding RNAs, such as long non-coding RNAs and small nucleolar RNAs. A DMR containing SLC9A3 had a minimum adjusted $p$-value $<10^{-6}$ and was demethylated, as was the marginally significant individual locus identified within the same gene. All significant DMRs, except for one, were demethylated in the high burden group compared to the control (Table 3).

An EWAS conducted with the whole blood data did not reveal any significantly methylated loci at the $5 \%$ FDR level. However, one CpG (cg13442689), which was associated with the gene PTPRN2, was marginally significantly hypermethylated $(q<=0.1)$. Closer evaluation of the 50 lowest $q$-values (Table 4$)$ revealed genes containing multiple loci. Two of the top 50 significantly methylated whole blood $\mathrm{CpGs}$ were located within MEST, MESTIT1 and were both more heavily methylated in the high burden group compared to the control. Also, RASA3 held two more of these top 50 significantly methylated whole blood $\mathrm{CpGs}$, and in each case they were hypomethylated in the high serum TCDD group compared to the controls. 
Our epigenome-wide analysis that adjusted for estimated leukocyte proportions in the whole blood data revealed no significantly methylated loci after accounting for multiple testing. Additionally, neither the proportions of cell types, the NLR, nor the LMR, significantly differed between the high dioxin burden group and the controls.

With low power to find associations between serum TCDD levels and methylation at individual loci at the genome-wide level, we used a candidate- $\mathrm{CpG}$ approach to compare the Ranch Hand data with that from the ACHS II [17]. Pittman et al. (2020) reported $116 \mathrm{CpG}$ loci were significantly associated with dioxin exposure at the $5 \%$ FDR level. Comparisons between the burden groups at each of these loci in the Ranch Hand data revealed one locus - cg20489453 - with significantly higher methylation levels $(p<0.05)$ associated with elevated serum TCDD concentrations. Four other $\mathrm{CpGs}$ were marginally significantly differentially methylated $(p<0.1)$ in the high burden versus control groups. Notably, four of the candidate CpGs were contained within the ALLC gene and were all hypomethylated in both the Ranch Hand and ACHS data. One of these loci located within ALLC (cg00999904) was marginally significantly demethylated in the high burden Ranch Hand veterans compared to the control group. In the ACHS, this locus in the ALLC gene had the greatest change in methylation between the exposed and control groups, and was demethylated [17].

We carried out additional analysis with the whole blood data for differentially methylated loci within the genes IGF2 and CYP1A1, which were targeted in a study of the peripheral blood of a group of people living in areas of Vietnam which were sprayed with Agent Orange [39]. Giuliani et al., 2018 provide evidence that loci within CYP1A1, but not IGF2, were altered with Agent Orange exposure. We found significant differences $(p<0.05)$ in methylation at multiple loci (cg00353139 and cg19817399) in the CYP1A1 gene in the high burden Ranch Hand veterans compared to the controls, although these differences were not systematic (i.e. methylation was not in the same direction between the two studies) and were consistent with the significance being the result of multiple comparisons. Similarly, though the loci (cg01351425 and cg00221747) we found to be significantly differently methylated $(p<0.05)$ in IGF2 in the highly burdened veterans compared to the control were both hypomethylated, these results were also consistent with arising as the result of multiple comparisons. In addition to CYP1A1, we explored other AHR pathway genes for differential methylation associated with serum dioxin levels. Ultimately, differences in methylation between the high and control dioxin groups in the genes of the AHR pathway were not significant when accounting for multiple comparisons (data not shown).

None of the DNA regions included in our DMRcate analysis in the whole blood data were significantly methylated between the high and control groups, by either the Stouffer-adjusted or minimum adjusted $p$ values.

There was no significant difference (t-test) in methylation age values using the Hannum, Horvath, and PhenoAge epigenetic clocks between the high serum TCDD and control groups in the whole blood data. Additionally, there was no correlation between methylation age and dioxin levels (modeled as a continuous variable). For each clock, only chronological age was significantly correlated with methylation 
age (Hannum clock: $r=0.900 p<0.01$; Horvath clock: $r=0.882, \mathrm{p}<0.01$; PhenoAge clock: $r=0.880, p<0.01$ ). Age acceleration was calculated by regressing methylation age on chronological age and taking the residuals of the model [44]. We constructed linear models with age acceleration as the outcome and dioxin level as the predictor (see methods). After adjusting for confounders, we determined that age acceleration was not associated with elevated serum dioxin levels. We repeated this analysis with the adipose tissue data (excluding the Hannum clock) and similarly observed no association of age acceleration with TCDD level, and only chronological age was significantly correlated with methylation age (Horvath: $r=0.855, p<0.01$; PhenoAge clock: $r=0.788, p<0.01$ ).

\section{Discussion}

We evaluated the DNA methylation of the adipose tissue and whole blood of a pilot-sized subset of Operation Ranch Hand veterans who were exposed to Agent Orange while serving in the Vietnam War. There were no significant TCDD-associated changes in the adipose tissue methylome at a genome-wide level after correcting for multiple comparisons. However, three individual loci in the adipose tissue were marginally significantly hypomethylated with increased serum TCDD levels. These three loci were contained within the genes SLC9A3, LYNX1, and TNRC18.

There is limited data on the biological role of SLC9A3, however, the gene encodes a membrane $\mathrm{Na} / \mathrm{H}$ exchanger 3 [45], and is associated with the RhoA GTPase signaling pathway [46]. The RhoA GTPase and its downstream targets regulate cell adherence, migration, and proliferation through actin-cytoskeletal modification, and abnormal activation of this pathway plays a role in several diseases [47], [48]. Interestingly, the aryl hydrocarbon (dioxin) receptor (AHR), which mediates the toxic effects of TCDD, interacts with the RhoA and Rac1 signaling pathways through the Vav3 exchange factor to influence cell morphology and adhesion, and positively regulates cell migration [49], [50]. While the impact of hypomethylation at cg18447419 on the action of AHR-mediated RhoA/Rac1 signaling is unknown, this CpG and SLC9A3 should be considered in future candidate analyses given the known interaction between this pathway and dioxin and its potential role in diseases like cancer.

Data suggest that dioxin exposure may play a role in modulating adipose tissue levels in the body. STAB1, which we discovered could be coordinately hypermethylated in the adipose tissue of the Ranch Hands compared to the control veterans, has been shown to be overexpressed in the white adipose tissue of rats exposed to TCDD [51]. This increased expression of STAB1 was likely induced by TCDD-related cell death in the adipose tissue, and the authors hypothesized that it could be associated with macrophage infiltration [51]. TCDD can induce fatal wasting syndrome in rats, characterized by loss of adipose and body weight, and increased serum lipid levels [7], [8], [52], and STAB1 overexpression could be associated with this degradation of stored fat that occurs with acute exposure to high levels of TCDD [9].

Mice chronically exposed to TCDD while being fed a high-fat diet showed significant weight gain and the development of an obese phenotype [9]. In contrast to this finding in mice, BMI was inversely associated 
with maternal TCDD concentration in daughters exposed in utero from a factory explosion in Seveso, Italy [10]. However, there was no such relationship in the sons exposed to TCDD in utero from the Seveso accident [10]. A prospective study of a cohort of adult French women found that higher estimated chronic dietary intake of dioxin was significantly associated with decreased BMI [53]. Data suggests that STAB1 expression levels are increased in the subcutaneous adipose tissue of obese compared to lean individuals [54]. Given that the present study found two of the top 50 altered adipose tissue CpGs to be hypermethylated in STAB1, this gene could have been suppressed with TCDD burden in the Ranch Hand veterans. If $S T A B 1$ overexpression is a marker for obesity, hypermethylation in this gene could be associated with a leaner body type in the veterans, similar to that of the French women chronically exposed to TCDD. However, no differences in BMI were observed between the Ranch Hand and control veterans when they were enrolled in the AFHS. This could have been complicated by the fact that BMI was measured in the enrolled veterans at least 11 years following their period of service.

When we applied the DMRcate algorithm to the adipose tissue data, 11 out of 46,470 searched regions were differently coordinately methylated in the high serum TCDD versus control groups by a minimum adjusted $p$-value $<10^{-6}$. The DMR associated with SLC9A3 was significantly differentially methylated, suggesting that loci across the gene were aberrantly altered with elevated serum dioxin levels, in addition to the single $\mathrm{CpG}$ discovered in our EWAS. Most of the other genes associated with the significantly methylated regions encoded non-coding RNAs. This is similar to our prior analysis of methylation in the sperm genome of these Ranch Hand veterans, where the gene H19, which encodes a long non-coding RNA (IncRNA), was altered [55]. Recent studies measuring the expression profile of IncRNAs suggest that these molecules could regulate gene expression related to the cellular responses to TCDD [56], [57]. Given this evidence that methylation and expression of genes encoding IncRNAs could be altered with TCDD to impact cellular processes, these regions of the genome could serve as candidate DMRs in future studies of the epigenetic effects of TCDD exposure.

We employed a similar agnostic approach to studying methylation at individual $\mathrm{CpGs}$ in the whole blood of the veterans. One $\mathrm{CpG}$, contained within PTPRN2, was marginally significantly differentially methylated in the highly burdened group compared to the control. In the sperm data from our previous analysis, PTPRN2 also contained a CpG that was one of the top 50 altered loci by change in beta value [55], suggesting that this gene could be aberrantly methylated with dioxin exposure in multiple tissues. Intriguingly, a study that searched the human genome for dioxin response elements - locations in the DNA where AHR binds to induce transcription - found PTPRN2 to contain more of these loci than any other gene [58]. Thus, PTPRN2 expression could be highly regulated by AHR and influenced by TCDD exposure. Seemingly no prior studies have examined the relationship between dioxin exposure and PTPRN2 methylation in whole blood. Still, given the evidence that the expression of PTPRN2 is influenced by AHR and that methylation within this gene could occur with exposure in multiple tissues, it warrants attention in future studies.

We studied the differences in whole blood methylation beta values between the highly burdened Ranch Hand and control veterans at each of the 116 differentially methylated CpGs with dioxin exposure in the 
Anniston adults [17]. We determined that one locus was hypomethylated in the highly burdened Ranch Hands compared to the control veterans. This locus is contained within the gene SMO, which codes for a 7-pass transmembrane G-protein coupled signal transduction molecule that is an important component to the hedgehog signaling pathway [59]. SMO and hedgehog family proteins are also implicated in the ERK signaling pathway, which is activated with TCDD exposure to mediate certain cell processes, including TNF-a production within white blood cells, like macrophages [60], [61]. It is unclear if, and how, hypomethylation at this specific locus within $S M O$ could impact dioxin action within the blood cells through these signaling pathways. Nevertheless, this finding is noteworthy since SMO could play a role in dioxin-mediated cell processes and the $\mathrm{CpG}$ described here was also differentially methylated in another dioxin exposure study (ACHS).

We further supported results from the ACHS through our discovery that all four of the candidate CpGs within $A L L C$ were hypomethylated in both the dioxin-exposed Anniston adults [17] and Ranch Hands veterans. Pittman et al. summarize that $A L L C$ is a gene in the uric acid degradation pathway, and is expressed in a variety of tissues [17]. Also, ALLC has been shown to be upregulated in CD34 + hematopoietic stem cells and progenitor cells after dioxin exposure [17], however the significance of this data as it pertains to the Ranch Hand veterans and the people living in Anniston is unclear and necessitates further investigation. Additionally, the CpG with the greatest change in methylation in the Anniston adults exposed to TCDD compared to the control group (cg00999904) was marginally significantly altered in the Ranch Hand veterans. This provides evidence that this $\mathrm{CpG}$, which is contained within $A L L C$, is particularly sensitive to TCDD, and should be included in further candidate analyses.

Review of the 2019 Comparative Toxicogenomics Database [62] confirmed TCDD interacts with some genes whose methylation was associated with serum TCDD levels in this study (SLC9A3, LYNX1, and TNRC18 from adipose tissue, and PTPRN2 from whole blood). This database review supports our data, further suggesting that these genes could be sensitive to alterations with dioxin exposure.

Since the environment has been shown to alter DNA methylation age [63], we investigated a possible association between biological age acceleration and TCDD burden in the Ranch Hand veterans. Biological age acceleration, defined as a positive difference between epigenetic age and chronological age, indicates increased risk for a host of poor health outcomes including cardiovascular disease, cancer, and premature death [64]-[66]. Using three different epigenetic clocks, we found no association between age acceleration and dioxin burden in the Ranch Hand veterans.

This study has some limitations. First, this was a pilot study with $37-42$ veterans. Thus, we were underpowered to detect epigenetic alterations at the genome-wide level. Additionally, the latency between the time of data collection in the AFHS from the original exposure could have impacted our results. Though the Ranch Hands served in Vietnam from 1962-1971, the AFHS did not commence until 1982 [24], and as TCDD has a half-life in humans of 7 to 11 years [1], the serum dioxin levels we obtained did not match those at exposure. Furthermore, error in the measurement tools used to find the serum TCDD 
concentrations also could have influenced our analysis. Finally, while we attempted to correct for confounders, residual confounding is possible.

\section{Conclusions}

We found limited evidence of epigenetic alterations associated with elevated serum TCDD levels in multiple tissues of Operation Ranch Hand Veterans. In our analysis of the data from the adipose tissue samples, we found the gene $S L C 9 A 3$ to be of interest for further study, as it showed significant methylation both in our CpG locus-by-locus and regional-scale tests. Also, STAB1 - a gene that is implicated in body fat content - was coordinately methylated in the adipose tissue. In the whole blood samples, we determined that a CpG within the gene PTPRN2, which contains numerous dioxin response elements, was methylated to marginal genome-wide significance. Finally, we replicated findings from the ACHS, obtaining evidence that a CpG within SMO - a gene implicated in the action of TCDD within cells [61] - was significantly hypomethylated in both the TCDD-exposed Anniston adults and Ranch Hand veterans. These data offer a better understanding of the impact of Agent Orange exposure on the methylome of Ranch Hand veterans, identifying candidate loci for future investigation.

\section{Abbreviations}

AFHS

Air Force Health Study

TCDD

2,3,7,8-tetrachlorodibenzo- $p$-dioxin

PCBs

Polychlorinated biphenyls

DMRs

Differentially methylated regions

EWAS

Epigenome wide association study

BMI

Body mass index

SVA

Surrogate variable analysis

$\mathrm{BH}$

Benjamini-Hochberg

FDR

False discovery rate

NLR

Neutrophil to lymphocyte ration

LMR 
Lymphocyte to monocyte ration

ACHS

Anniston community health survey

LSDL

Lipid-adjusted serum dioxin levels

AHR

Aryl hydrocarbon receptor

IncRNA

long non-coding RNA

\section{Declarations}

\section{Ethics approval and consent to participate}

This research was approved by the Brown University IRB.

Consent for publication

Not applicable

\section{Availability of data and materials}

Data from the Anniston Community Health Survey that was analyzed in this research is available in the associated publication [15]. Data generated and analyzed from the Ranch Hand Veterans is available upon request from the corresponding author.

\section{Competing interests}

KTK is a founder and advisor for Cellintec. Brown University was compensated for JMB's services as an expert witness for plaintiffs in litigation related to PFAS-contaminated drinking water; these funds were not paid to JMB directly. JMB received an honorarium for serving on an advisory board to Quest Diagnostics. The other authors declare they have no actual or potential competing financial interests.

\section{Funding}

This work was funded in part from a grant from the National Academy of Sciences.

\section{Author's Contributions}

KTK conceived of the research. MRR, ME, and EAH conducted the analysis. RB conducted the laboratory work. MRR drafted the manuscript with assistance from RB, JMB, and KTK. All authors read and approved the final manuscript.

\section{Acknowledgements}


The authors acknowledge the assistance of Edward Dere and Kim Boekelheide of the Brown University School of Public Health, and Susan M. Huse of the National Institute of Allergy and Infectious Diseases.

\section{Footnotes}

Not applicable.

\section{References}

[1] The National Academy of Sciences, Ed., Veterans and Agent Orange: Update 11 (2018). Washington, DC: The National Academies Press, 2018.

[2] E. J. Mrema, F. M. Rubino, G. Brambilla, A. Moretto, A. M. Tsatsakis, and C. Colosio, "Persistent organochlorinated pesticides and mechanisms of their toxicity," Toxicology, 2013, doi: 10.1016/j.tox.2012.11.015.

[3] B. Patrizi and M. S. de Cumis, "TCDD toxicity mediated by epigenetic mechanisms," International Journal of Molecular Sciences. 2018, doi: 10.3390/ijms19124101.

[4] P. A. Buffler, M. E. Ginevan, J. S. Mandel, and D. K. Watkins, "The Air Force Health Study: An Epidemiologic Retrospective," Annals of Epidemiology. 2011, doi: 10.1016/j.annepidem.2011.02.001.

[5] J. K. Sethi and A. J. Vidal-Puig, "Thematic review series: Adipocyte Biology. Adipose tissue function and plasticity orchestrate nutritional adaptation," Journal of Lipid Research. 2007, doi: 10.1194/jlr.R700005-JLR200.

[6] L. Luo and M. Liu, "Adipose tissue in control of metabolism," Journal of Endocrinology. 2016, doi: 10.1530/JOE-16-0211.

[7] M. D. Seefeld, S. W. Corbett, R. E. Keesey, and R. E. Peterson, "Characterization of the wasting syndrome in rats treated with 2,3,7,8-tetrachlorodibenzo-p-dioxin," Toxicol. Appl. Pharmacol., 1984, doi: 10.1016/0041-008X(84)90337-5.

[8] S. B. Magesh, R. Rajappa, K. M. Ramkumar, S. Suryanarayanan, and S. V. Madhunapantula, "Acetyl-LCarnitine Restores Abnormal Lipid Metabolism Induced by 2,3,7,8-Tetrachlorodibenzo-P-Dioxin in Mice," Biomed. Pharmacol. J., 2017.

[9] A. Brulporta, L. Le Correa, and M.-C. Chagnon, "Chronic exposure of 2,3,7,8-tetrachlorodibenzo-p-dioxin (TCDD) induces an obesogenic effect in C57BL/6J mice fed a high fat diet," Toxicology, 2017.

[10] M. Warner et al., "In utero dioxin exposure and cardiometabolic risk in the Seveso Second Generation Study," Int. J. Obes., 2019, doi: 10.1038/s41366-018-0306-8. 
[11] M. W. van den Dungen, A. J. Murk, D. E. Kok, and W. T. Steegenga, “Persistent organic pollutants alter DNA methylation during human adipocyte differentiation," Toxicol. Vitr., 2017, doi:

10.1016/j.tiv.2016.12.011.

[12] L. Bastos Sales, J. H. Kamstra, P. H. Cenijn, L. S. van Rijt, T. Hamers, and J. Legler, "Effects of endocrine disrupting chemicals on in vitro global DNA methylation and adipocyte differentiation," Toxicol. Vitr., 2013, doi: 10.1016/j.tiv.2013.04.005.

[13] H. F. Hsu, T. C. Tsou, H. R. Chao, Y. T. Kuo, F. Y. Tsai, and S. C. Yeh, “Effects of 2,3,7,8tetrachlorodibenzo-p-dioxin on adipogenic differentiation and insulin-induced glucose uptake in 3T3-L1 cells," J. Hazard. Mater., 2010, doi: 10.1016/j.jhazmat.2010.06.081.

[14] M. J. Kim et al., "Inflammatory pathway genes belong to major targets of persistent organic pollutants in adipose cells," Environ. Health Perspect., 2012, doi: 10.1289/ehp.1104282.

[15] E. A. Houseman, S. Kim, K. T. Kelsey, and J. K. Wiencke, "DNA Methylation in Whole Blood: Uses and Challenges," Current environmental health reports. 2015, doi: 10.1007/s40572-015-0050-3.

[16] G. S. Pittman et al., "Polychlorinated biphenyl exposure and DNA methylation in the Anniston Community Health Survey," Epigenetics, 2019, doi: 10.1080/15592294.2019.1666654.

[17] G. S. Pittman et al., "Dioxin-like compound exposures and DNA methylation in the Anniston Community Health Survey Phase II," Sci. Total Environ., 2020.

[18] M. W. van den Dungen, A. J. Murk, E. Kampman, W. T. Steegenga, and D. E. Kok, "Association between DNA methylation profiles in leukocytes and serum levels of persistent organic pollutants in Dutch men," Environ. Epigenetics, 2017, doi: 10.1093/eep/dvx001.

[19] K. Y. Su et al., "Perinatal polychlorinated biphenyls and polychlorinated dibenzofurans exposure are associated with DNA methylation changes lasting to early adulthood: Findings from Yucheng second generation," Environ. Res., 2019, doi: 10.1016/j.envres.2019.01.001.

[20] M. H. Lee, E. R. Cho, J. eun Lim, and S. H. Jee, "Association between serum persistent organic pollutants and DNA methylation in Korean adults," Environ. Res., 2017, doi:

10.1016/j.envres.2017.06.017.

[21] H. Itoh et al., "Association between serum organochlorines and global methylation level of leukocyte DNA among Japanese women: A cross-sectional study," Sci. Total Environ., 2014, doi: 10.1016/j.scitotenv.2014.05.035.

[22] G. D. Lathrop, W. H. Wolfe, R. A. Albanese, and P. M. Moynahan, "An epidemiologic investigation of health effects in Air Force personnel following exposure to herbicides: Study protocol, initial report.," Brooks Air Force Base, TX, 1982. 
[23] G. D. Lathrop, P. M. Moynahan, R. A. Albanese, and W. H. Wolfe, "An epidemiologic investigation of health effects in Air Force personnel following exposure to herbicides: Baseline morbidity study results.," Brooks Air Force Base, TX, 1984.

[24] Committee on the Management of the Air Force Health Study Data and Specimens, The Air Force Health Study Assets Research Program. Washington, DC: National Academies Press, 2015.

[25] C. on the D. of the A. F. H. S. Institute of Medicine, Board on Population Health and Public Health Practice, Disposition of the Air Force Health Study. Washington, DC: National Academies Press, 2006.

[26] C. for D. C. U.S Department of Health and Human Services, Public Health Service, "Health Status of Vietnam Veterans: Supplement A - Laboratory Methods and Quality Control," Atlanta, 1989.

[27] Science Applications International Corporation, "Biomedical Test Plan. Air Force Contract No. F14689-85-D-0010," 1985.

[28] R Core Team, R: A Language and Environment for Statistical Computing. Vienna, Austria, 2019.

[29] C. S. Wilhelm-Benartzi et al., "Review of processing and analysis methods for DNA methylation array data," British Journal of Cancer. 2013, doi: 10.1038/bjc.2013.496.

[30] Y. A. Chen et al., "Discovery of cross-reactive probes and polymorphic CpGs in the Illumina Infinium HumanMethylation450 microarray," Epigenetics, 2013, doi: 10.4161/epi.23470.

[31] T. J. Triche, D. J. Weisenberger, D. Van Den Berg, P. W. Laird, and K. D. Siegmund, "Low-level processing of Illumina Infinium DNA Methylation BeadArrays," Nucleic Acids Res., 2013, doi: 10.1093/nar/gkt090.

[32] J. P. Fortin et al., "Functional normalization of $450 \mathrm{k}$ methylation array data improves replication in large cancer studies," Genome Biol., 2014, doi: 10.1186/s13059-014-0503-2.

[33] A. E. Teschendorff et al., "A beta-mixture quantile normalization method for correcting probe design bias in Illumina Infinium 450 k DNA methylation data," Bioinformatics, 2013, doi: 10.1093/bioinformatics/bts680.

[34] C. Chen et al., "Removing batch effects in analysis of expression microarray data: An evaluation of six batch adjustment methods," PLoS One, 2011, doi: 10.1371/journal.pone.0017238.

[35] J. T. Leek and J. D. Storey, "Capturing heterogeneity in gene expression studies by surrogate variable analysis," PLoS Genet., 2007, doi: 10.1371/journal.pgen.0030161.

[36] S. Mallik, G. J. Odom, Z. Gao, L. Gomez, X. Chen, and L. Wang, "An evaluation of supervised methods for identifying differentially methylated regions in Illumina methylation arrays," Brief. Bioinform., 2019, doi: 10.1093/bib/bby085. 
[37] J. K. Wiencke et al., "Immunomethylomic approach to explore the blood neutrophil lymphocyte ratio (NLR) in glioma survival," Clin. Epigenetics, 2017, doi: 10.1186/s13148-017-0316-8.

[38] S. Ambatipudi et al., "DNA methylation derived systemic inflammation indices are associated with head and neck cancer development and survival," Oral Oncol., 2018, doi:

10.1016/j.oraloncology.2018.08.021.

[39] C. Giuliani et al., "First evidence of association between past environmental exposure to dioxin and DNA methylation of CYP1A1 and IGF2 genes in present day Vietnamese population," Environ. Pollut., 2018, doi: 10.1016/j.envpol.2018.07.015.

[40] G. Hannum et al., "Genome-wide Methylation Profiles Reveal Quantitative Views of Human Aging Rates," Mol. Cell, 2013, doi: 10.1016/j.molcel.2012.10.016.

[41] C. G. Bell et al., "DNA methylation aging clocks: Challenges and recommendations," Genome Biology. 2019, doi: 10.1186/s13059-019-1824-y.

[42] S. Horvath, "DNA methylation age of human tissues and cell types," Genome Biol., 2013, doi: 10.1186/gb-2013-14-10-r115.

[43] M. E. Levine et al., "An epigenetic biomarker of aging for lifespan and healthspan," Aging (Albany. NY)., 2018, doi: 10.18632/aging.101414.

[44] A. J. White et al., "Air pollution, particulate matter composition and methylation-based biologic age," Environ. Int., 2019, doi: 10.1016/j.envint.2019.105071.

[45] R. G. Fehon, A. I. McClatchey, and A. Bretscher, "Organizing the cell cortex: The role of ERM proteins," Nature Reviews Molecular Cell Biology. 2010, doi: 10.1038/nrm2866.

[46] A. D. Rouillard et al., "The harmonizome: a collection of processed datasets gathered to serve and mine knowledge about genes and proteins," Database (Oxford)., 2016, doi: 10.1093/database/baw100.

[47] L. Yao, M. J. Romero, H. A. Toque, G. Yang, R. B. Caldwell, and R. W. Caldwell, "The role of RhoA/Rho kinase pathway in endothelial dysfunction," J. Cardiovasc. Dis. Res., vol. 1, no. 4, pp. 165-170, 2010, doi: 10.4103/0975-3583.74258.

[48] W. Chen, K. Mao, Z. Liu, A. Tuan, and Dinh-Xuan, "The role of the RhoA/Rho kinase pathway in anti-angiogenesis and its potential value in prostate cancer (Review)," Oncol. Lett., 2014.

[49] J. M. Carvajal-Gonzalez et al., "The dioxin receptor regulates the constitutive expression of the Vav3 proto-oncogene and modulates cell shape and adhesion," Mol. Biol. Cell, 2009, doi: 10.1091/mbc.E08-050451. 
[50] P. M. Fernandez-Salguero, "A remarkable new target gene for the dioxin receptor: The Vav3 protooncogene links AhR to adhesion and migration," Cell Adhesion and Migration. 2010, doi: 10.4161/cam.4.2.10387.

[51] K. E. Houlahan et al., "Transcriptional profiling of rat hypothalamus response to 2,3,7,8tetrachlorodibenzo-p-dioxin," Toxicology, 2015, doi: 10.1016/j.tox.2014.12.016.

[52] J. T. Tuomisto, R. Pohjanvirta, M. Unkila, and J. Tuomisto, "TCDD-induced anorexia and wasting syndrome in rats: Effects of diet-induced obesity and nutrition," Pharmacol. Biochem. Behav., 1999, doi: 10.1016/S0091-3057(98)00224-X.

[53] A. M. N. Danjou, B. Fervers, M. C. Boutron-Ruault, T. Philip, F. Clavel-Chapelon, and L. Dossus, "Estimated dietary dioxin exposure and breast cancer risk among women from the French E3N prospective cohort," Breast Cancer Res., 2015, doi: 10.1186/s13058-015-0536-9.

[54] D. Schleinitz et al., "Fat depot-specific mRNA expression of novel loci associated with waist-hip ratio," Int. J. Obes., 2014, doi: 10.1038/ijo.2013.56.

[55] K. T. Kelsey et al., "Serum dioxin and DNA methylation in the sperm of operation ranch hand veterans exposed to Agent Orange," Environ. Heal. A Glob. Access Sci. Source, 2019, doi: 10.1186/s12940-0190533-z.

[56] M. Ruszkowska et al., "Identification and characterization of long non-coding RNAs in porcine granulosa cells exposed to 2,3,7,8-tetrachlorodibenzo-p-dioxin," J. Anim. Sci. Biotechnol., 2018, doi: 10.1186/s40104-018-0288-3.

[57] J. L. Dempsey and J. Y. Cui, "Long non-coding RNAs: A novel paradigm for toxicology," Toxicological Sciences. 2017, doi: 10.1093/toxsci/kfw203.

[58] E. Dere, A. L. Forgacs, T. R. Zacharewski, and L. D. Burgoon, "Genome-wide computational analysis of dioxin response element location and distribution in the human, mouse, and rat genomes," Chem. Res. Toxicol., 2011, doi: 10.1021/tx100328r.

[59] A. Hanna and L. A. Shevde, "Hedgehog signaling: Modulation of cancer properies and tumor mircroenvironment," Molecular Cancer. 2016, doi: 10.1186/s12943-016-0509-3.

[60] H. J. Cheon et al., "Signaling pathway for 2,3,7,8-tetrachlorodibenzo-p-dioxin-induced TNF-a production in differentiated THP-1 human macrophages," Exp. Mol. Med., 2007, doi: 10.1038/emm.2007.58.

[61] P. R. Hanlon, L. G. Ganem, Y. C. Cho, M. Yamamoto, and C. R. Jefcoate, "AhR- and ERK-dependent pathways function synergistically to mediate 2,3,7,8-tetrachlorodibenzo-p-dioxin suppression of peroxisome proliferator-activated receptor- $\gamma 1$ expression and subsequent adipocyte differentiation," Toxicol. Appl. Pharmacol., 2003, doi: 10.1016/S0041-008X(03)00083-8. 
[62] A. P. Davis et al., "The Comparative Toxicogenomics Database: Update 2019," Nucleic Acids Res., 2019, doi: 10.1093/nar/gky868.

[63] R. Dhingra, J. C. Nwanaji-Enwerem, M. Samet, and C. K. Ward-Caviness, "DNA Methylation AgeEnvironmental Influences, Health Impacts, and Its Role in Environmental Epidemiology," Current environmental health reports. 2018, doi: 10.1007/s40572-018-0203-2.

[64] L. Perna, Y. Zhang, U. Mons, B. Holleczek, K. U. Saum, and H. Brenner, “Epigenetic age acceleration predicts cancer, cardiovascular, and all-cause mortality in a German case cohort," Clin. Epigenetics, 2016, doi: 10.1186/s13148-016-0228-z.

[65] N. S. Roetker, J. S. Pankow, J. Bressler, A. C. Morrison, and E. Boerwinkle, "Prospective Study of Epigenetic Age Acceleration and Incidence of Cardiovascular Disease Outcomes in the ARIC Study (Atherosclerosis Risk in Communities)," Circ. Genomic Precis. Med., 2018, doi:

10.1161/CIRCGEN.117.001937.

[66] D. F. Durso et al., "Acceleration of leukocytes' epigenetic age as an early tumorand sex-specific marker of breast and colorectal cancer," Oncotarget, 2017, doi: 10.18632/oncotarget.15573.

\section{Tables}

Table 1. Demographic data in each burden group in the adipose and whole blood tissue categories. 


\begin{tabular}{|c|c|c|c|c|c|}
\hline Adipose & $\begin{array}{l}\text { Control } \\
(\mathrm{N}=12)\end{array}$ & Low $(\mathrm{N}=3)$ & $\begin{array}{l}\text { Medium } \\
(\mathrm{N}=11)\end{array}$ & High (N=11) & All $(\mathrm{N}=37)$ \\
\hline $\begin{array}{l}\text { Age [Mean (SD)] } \\
\text { (yrs) }\end{array}$ & 70.5 (6.5) & $\begin{array}{l}81.7 \\
(11.6)\end{array}$ & 77.0 (8.5) & $67.7(1.9)$ & 72.5 (7.9) \\
\hline Smoking: ever [N (\%)] & $9(75.0)$ & $2(66.7)$ & $8(72.7)$ & $8(72.7)$ & $27(73.0)$ \\
\hline $\begin{array}{l}\text { BMI [Mean (SD)] } \\
\left(\mathrm{kg} / \mathrm{m}^{\wedge} 2\right)\end{array}$ & $32.1(5.5)$ & $24.9(1.0)$ & $30.9(3.7)$ & $30.9(3.3)$ & $30.8(4.4)$ \\
\hline $\begin{array}{l}\text { Dioxin [Mean (SD), } \\
\text { Range] (ppt) }\end{array}$ & $\begin{array}{l}4.2(1.3) \\
2.2-7.1\end{array}$ & $\begin{array}{l}6.7(0.9) \\
5.6-7.2\end{array}$ & $\begin{array}{l}13.4(3.3) \\
8.9-19.6\end{array}$ & $\begin{array}{l}66.4(48.6) \\
26.6-167.6\end{array}$ & $\begin{array}{l}25.6(37.4), \\
2.2-167.6\end{array}$ \\
\hline Whole Blood & $\begin{array}{l}\text { Control } \\
(\mathrm{N}=12)\end{array}$ & Low $(\mathrm{N}=4)$ & $\begin{array}{l}\text { Medium } \\
(\mathrm{N}=11)\end{array}$ & High (N=15) & All $(N=42)$ \\
\hline $\begin{array}{l}\text { Age [Mean (SD)] } \\
\text { (yrs) }\end{array}$ & $70.6(6.5)$ & $\begin{array}{l}79.5 \\
(10.4)\end{array}$ & $77.0(8.5)$ & $69.7(5.8)$ & $72.8(7.9)$ \\
\hline Smoking: ever [N (\%)] & $9(75.0)$ & $3(75.0)$ & $8(72.7)$ & $11(73.3)$ & $31(73.8)$ \\
\hline $\begin{array}{l}\text { BMI [Mean (SD)] } \\
\left(\mathrm{kg} / \mathrm{m}^{\wedge} 2\right)\end{array}$ & $32.1(5.5)$ & $25.7(1.8)$ & $30.9(3.7)$ & $29.7(3.5)$ & $30.3(4.4)$ \\
\hline $\begin{array}{l}\text { Dioxin [Mean (SD), } \\
\text { Range] (ppt) }\end{array}$ & $\begin{array}{l}4.2(1.3) \\
2.2-7.1\end{array}$ & $\begin{array}{l}6.5(0.8) \\
5.6-7.2\end{array}$ & $\begin{array}{l}\text { 13.4 (3.3), } \\
8.9-19.6\end{array}$ & $\begin{array}{l}60.4(42.3) \\
26.6-167.6\end{array}$ & $\begin{array}{l}26.9(35.6), \\
2.21-167.6\end{array}$ \\
\hline
\end{tabular}

Note: Demographic data from the Ranch Hand and control veterans was gathered as part of the Air Force Health Study. The burden groups are stratified by lipid-adjusted serum dioxin levels.

Table 2. Top 50 methylated adipose loci in the highly burdened veterans, ordered by $q$-value. 


\begin{tabular}{|c|c|c|c|c|c|}
\hline CpG & Chromosome & Gene & $\begin{array}{l}\text { Regression } \\
\text { Coeff. }\end{array}$ & pval & qval \\
\hline $\operatorname{cg} 18447419$ & 5 & SLC9A3 & -0.0951 & $\begin{array}{l}1.07 \mathrm{E}- \\
07\end{array}$ & 0.052 \\
\hline $\operatorname{cg} 04350571$ & 8 & LYNX1 & -0.0201 & $\begin{array}{l}5.97 \mathrm{E}- \\
07\end{array}$ & 0.100 \\
\hline cg04939944 & 7 & TNRC18 & -0.0302 & $\begin{array}{l}6.20 \mathrm{E}- \\
07\end{array}$ & 0.100 \\
\hline cg26351451 & 4 & KIAA1239 & 0.0364 & $\begin{array}{l}1.10 \mathrm{E}- \\
06\end{array}$ & 0.134 \\
\hline $\operatorname{cg} 10831901$ & 20 & LOC149837 & -0.0773 & $\begin{array}{l}1.44 \mathrm{E}- \\
06\end{array}$ & 0.140 \\
\hline $\operatorname{cg} 07327335$ & 2 & PP14571,GPC1 & -0.0466 & $\begin{array}{l}1.91 \mathrm{E}- \\
06\end{array}$ & 0.155 \\
\hline cg09130535 & 11 & ADRBK1 & -0.0197 & $\begin{array}{l}3.11 \mathrm{E}- \\
06\end{array}$ & 0.213 \\
\hline $\operatorname{cg} 14633910$ & 6 & SYCP2L & -0.0253 & $\begin{array}{l}4.40 \mathrm{E}- \\
06\end{array}$ & 0.213 \\
\hline $\operatorname{cg} 25679766$ & 6 & & 0.0315 & $\begin{array}{l}4.43 \mathrm{E}- \\
06\end{array}$ & 0.213 \\
\hline $\operatorname{cg} 18584639$ & 5 & & 0.0346 & $\begin{array}{l}4.54 \mathrm{E}- \\
06\end{array}$ & 0.213 \\
\hline $\operatorname{cg} 23045716$ & 4 & $\begin{array}{l}\text { LOC100130872,LOC100130872- } \\
\text { SPON2 }\end{array}$ & 0.0227 & $\begin{array}{l}5.10 \mathrm{E}- \\
06\end{array}$ & 0.213 \\
\hline $\operatorname{cg} 21726840$ & 19 & PRAM1 & 0.0237 & $\begin{array}{l}5.26 \mathrm{E}- \\
06\end{array}$ & 0.213 \\
\hline $\operatorname{cg} 26132511$ & 6 & ZFAND3 & 0.0231 & $\begin{array}{l}8.33 \mathrm{E}- \\
06\end{array}$ & 0.292 \\
\hline $\operatorname{cg} 12520727$ & 11 & CLPB & -0.0226 & $\begin{array}{l}8.78 \mathrm{E}- \\
06\end{array}$ & 0.292 \\
\hline $\operatorname{cg} 01026256$ & 3 & VWA5B2,MIR1224 & -0.0441 & $\begin{array}{l}9.11 \mathrm{E}- \\
06\end{array}$ & 0.292 \\
\hline $\operatorname{cg} 13983779$ & 9 & & -0.0245 & $\begin{array}{l}9.63 \mathrm{E}- \\
06\end{array}$ & 0.292 \\
\hline $\operatorname{cg} 06647068$ & 12 & CHST11 & -0.0341 & $\begin{array}{l}1.14 \mathrm{E}- \\
05\end{array}$ & 0.314 \\
\hline $\operatorname{cg} 10422455$ & 11 & MRGPRX2 & 0.0252 & $\begin{array}{l}1.16 \mathrm{E}- \\
05\end{array}$ & 0.314 \\
\hline $\operatorname{cg} 05361530$ & 16 & & 0.0217 & $1.31 \mathrm{E}-$ & 0.320 \\
\hline
\end{tabular}




\begin{tabular}{|c|c|c|c|c|c|}
\hline & & & & 05 & \\
\hline cg07392385 & 10 & SORCS1 & -0.0327 & $\begin{array}{l}1.34 \mathrm{E}- \\
05\end{array}$ & 0.320 \\
\hline cg13689342 & 21 & & 0.0202 & $\begin{array}{l}1.42 \mathrm{E}- \\
05\end{array}$ & 0.320 \\
\hline cg09977640 & 17 & & -0.0291 & $\begin{array}{l}1.55 \mathrm{E}- \\
05\end{array}$ & 0.320 \\
\hline cg13905238 & 3 & & -0.0310 & $\begin{array}{l}1.55 \mathrm{E}- \\
05\end{array}$ & 0.320 \\
\hline cg05060534 & 13 & TFDP1 & -0.0140 & $\begin{array}{l}1.61 \mathrm{E}- \\
05\end{array}$ & 0.320 \\
\hline cg16156617 & 6 & SLC17A4 & 0.0212 & $\begin{array}{l}1.67 \mathrm{E}- \\
05\end{array}$ & 0.320 \\
\hline cg09897374 & 6 & & 0.0364 & $\begin{array}{l}1.72 \mathrm{E}- \\
05\end{array}$ & 0.320 \\
\hline cg17094014 & 6 & MDFI & -0.0219 & $\begin{array}{l}1.88 \mathrm{E}- \\
05\end{array}$ & 0.338 \\
\hline cg07325692 & 7 & & 0.0268 & $\begin{array}{l}2.08 \mathrm{E}- \\
05\end{array}$ & 0.351 \\
\hline cg25195158 & 12 & & -0.0274 & $\begin{array}{l}2.15 \mathrm{E}- \\
05\end{array}$ & 0.351 \\
\hline cg18099408 & 3 & STAB1 & 0.0304 & $\begin{array}{l}2.22 \mathrm{E}- \\
05\end{array}$ & 0.351 \\
\hline cg20266320 & 1 & & -0.0330 & $\begin{array}{l}2.31 \mathrm{E}- \\
05\end{array}$ & 0.351 \\
\hline cg26284544 & 19 & SNAPC2 & -0.0678 & $\begin{array}{l}2.38 \mathrm{E}- \\
05\end{array}$ & 0.351 \\
\hline cg04307083 & 4 & HOPX & 0.0190 & $\begin{array}{l}2.38 \mathrm{E}- \\
05\end{array}$ & 0.351 \\
\hline cg09167779 & 5 & MCC & 0.0200 & $\begin{array}{l}2.48 \mathrm{E}- \\
05\end{array}$ & 0.354 \\
\hline cg13731106 & 9 & & 0.0257 & $\begin{array}{l}2.78 \mathrm{E}- \\
05\end{array}$ & 0.358 \\
\hline cg21207003 & 3 & QTRTD1 & -0.0198 & $\begin{array}{l}2.82 \mathrm{E}- \\
05\end{array}$ & 0.358 \\
\hline cg10891482 & 11 & MS4A8B & 0.0226 & $\begin{array}{l}3.01 \mathrm{E}- \\
05\end{array}$ & 0.358 \\
\hline cg01540102 & 16 & DOK4 & -0.0285 & $\begin{array}{l}3.03 \mathrm{E}- \\
05\end{array}$ & 0.358 \\
\hline
\end{tabular}




\begin{tabular}{|c|c|c|c|c|c|}
\hline $\operatorname{cg} 11404049$ & 1 & CASP9 & -0.0141 & $\begin{array}{l}3.10 \mathrm{E}- \\
05\end{array}$ & 0.358 \\
\hline cg08644276 & 2 & & 0.0265 & $\begin{array}{l}3.12 \mathrm{E}- \\
05\end{array}$ & 0.358 \\
\hline cg16763089 & 20 & LOC149837 & -0.0868 & $\begin{array}{l}3.17 \mathrm{E}- \\
05\end{array}$ & 0.358 \\
\hline $\operatorname{cg} 15791105$ & 12 & COL2A1 & 0.0159 & $\begin{array}{l}3.18 \mathrm{E}- \\
05\end{array}$ & 0.358 \\
\hline cg25965864 & 12 & LRRC23 & -0.0235 & $\begin{array}{l}3.25 \mathrm{E}- \\
05\end{array}$ & 0.358 \\
\hline $\operatorname{cg} 07860645$ & 6 & DAAM2 & -0.0234 & $\begin{array}{l}3.37 \mathrm{E}- \\
05\end{array}$ & 0.358 \\
\hline cg16673904 & 17 & SHBG & 0.0199 & $\begin{array}{l}3.39 \mathrm{E}- \\
05\end{array}$ & 0.358 \\
\hline cg23477257 & 7 & PHTF2 & 0.0214 & $\begin{array}{l}3.39 \mathrm{E}- \\
05\end{array}$ & 0.358 \\
\hline cg05053979 & 14 & FOXN3 & -0.0352 & $\begin{array}{l}3.59 \mathrm{E}- \\
05\end{array}$ & 0.365 \\
\hline cg01330280 & 6 & HIST1H3H,HIST1H2BL & -0.0547 & $\begin{array}{l}3.65 \mathrm{E}- \\
05\end{array}$ & 0.365 \\
\hline $\operatorname{cg} 15147215$ & 3 & STAB1 & 0.0218 & $\begin{array}{l}3.83 \mathrm{E}- \\
05\end{array}$ & 0.365 \\
\hline cg09357935 & 11 & SLC6A5 & -0.0453 & $\begin{array}{l}3.85 \mathrm{E}- \\
05\end{array}$ & 0.365 \\
\hline
\end{tabular}

Note: Data generated from a linear model with empirical Bayes estimation, which we used for the adipose tissue DNA methylation beta value comparisons between the Ranch Hand veterans with high serum TCDD levels $(n=11)$ and the control group $(n=12)$. The $q$-value was calculated using the BenjaminiHochberg method. The regression coefficient identifies the direction of methylation change between the burden groups and was determined via the model we constructed. Genes associated with each CpG are also given in the table.

Table 3. Regions of adipose tissue DNA altered in the high burden group compared to the control that resulted in a minimum adjusted $p$-value $<10^{-6}$. 


\begin{tabular}{|c|c|c|c|c|c|c|}
\hline Chrm. & $\begin{array}{l}\text { Number } \\
\text { of } \\
\text { CpGs }\end{array}$ & pval & $\begin{array}{l}\text { Stouffer- } \\
\text { adjusted } \\
\text { pval }\end{array}$ & $\begin{array}{l}\text { Max } \\
\text { beta- } \\
\text { fold } \\
\text { change }\end{array}$ & $\begin{array}{l}\text { Mean } \\
\text { beta- } \\
\text { fold } \\
\text { change }\end{array}$ & Overlapping Genes \\
\hline 2 & 9 & $\begin{array}{l}8.26 \mathrm{E}- \\
15\end{array}$ & 1 & -0.077 & -0.057 & $\begin{array}{l}\text { SNORA64, SNORA12, SNORA74, } \\
\text { SNORA19, PAX8-AS1, SnR65, } \\
\text { 5S_rRNA, SNORA4, SNORD11, } \\
\text { SNORD51, SNORA41, SCARNA6, } \\
\text { SNORD39, SNORA75, ACA59, PAX8, } \\
\text { SNORA48, SNORD56, SNORA43, } \\
\text { SNORA1, Vault }\end{array}$ \\
\hline 13 & 5 & $\begin{array}{l}8.32 \mathrm{E}- \\
13\end{array}$ & 1 & -0.046 & -0.038 & SNORD36 \\
\hline 1 & 8 & $\begin{array}{l}7.11 \mathrm{E}- \\
11\end{array}$ & 1 & -0.058 & -0.027 & $\begin{array}{l}\text { SnoU13, Y_RNA, SCARNA16, U1, } \\
\text { SCARNA17, SCARNA18, SCARNA24, } \\
\text { SNORD112, SNORA62, SNORA63, } \\
\text { C10rf50, SNORD46, SNORA2, } \\
\text { SNORD81, U3, SNORA51, SNORA25, } \\
\text { SCARNA20, SNORA67, U6, SNORA70, } \\
\text { SNORA77, SNORA26, U8, SCARNA11, } \\
\text { SNORA31, SNORA42, SNORA40, } \\
\text { SNORD64, ACA64, snoU109, } \\
\text { SNORD60, SNORD116 }\end{array}$ \\
\hline 20 & 9 & $\begin{array}{l}7.97 \mathrm{E}- \\
11\end{array}$ & 1 & -0.076 & -0.053 & LINC00654 \\
\hline 6 & 21 & $\begin{array}{l}3.67 \mathrm{E}- \\
09\end{array}$ & 1 & -0.050 & -0.024 & SNORA38, LY6G5C, SNORA20 \\
\hline 19 & 25 & $\begin{array}{l}1.76 \mathrm{E}- \\
08\end{array}$ & 1 & -0.035 & -0.011 & USP29 \\
\hline 1 & 5 & $\begin{array}{l}1.83 \mathrm{E}- \\
08\end{array}$ & 1 & -0.058 & -0.044 & $\begin{array}{l}\text { SnoU13, Y_RNA, SCARNA16, } \\
\text { SCARNA21, U1, SCARNA17, } \\
\text { SCARNA18, SCARNA24, SNORD112, } \\
\text { SNORA62, SNORA63, SNORD46, } \\
\text { SNORA2, SNORD81, U3, SNORA51, } \\
\text { SNORA25, SCARNA20, SNORA67, U6, } \\
\text { SNORA70, SNORA77, SNORA26, U8, } \\
\text { SCARNA11, SNORA31, SNORA42, } \\
\text { SNORA40, SNORD64, ACA64, } \\
\text { snoU109, SNORD60 }\end{array}$ \\
\hline 5 & 12 & $\begin{array}{l}2.98 \mathrm{E}- \\
08\end{array}$ & 1 & -0.068 & -0.014 & SLC9A3 \\
\hline 17 & 12 & $\begin{array}{l}6.86 \mathrm{E}- \\
08\end{array}$ & 1 & -0.058 & -0.025 & C17orf107, CHRNE \\
\hline 7 & 16 & $\begin{array}{l}9.88 \mathrm{E}- \\
08\end{array}$ & 1 & 0.071 & 0.013 & YWHAG \\
\hline 11 & 10 & $\begin{array}{l}1.61 \mathrm{E}- \\
07\end{array}$ & 1 & -0.042 & -0.030 & LSP1, SLC6A5 \\
\hline
\end{tabular}


Note: Data generated using the DMRcate algorithm from Bioconductor. The "pval" is a minimum adjusted $p$-value generated by the DMRcate algorithm, and we used a significance cutoff of $1 \mathrm{e}-6$ when comparing methylation across the adipose tissue DNA regions in the Ranch Hand veterans with high serum TCDD $(n=11)$ levels compared to the control group $(n=12)$. The Stouffer-adjusted $p$-value is also calculated by DMRcate. The max and mean beta-fold change indicate differences in methylation levels between the highly burdened and control groups. The "Overlapping Genes" column indicates the genes associated with the region of DNA studied.

Table 4 . The top 50 differentially methylated CpGs in whole blood, ordered by $q$-value, when comparing the high and control burden groups. 


\begin{tabular}{|c|c|c|c|c|c|}
\hline CpG & CHR & Gene & Regression Coeff. & pval & qval \\
\hline cg13442689 & 7 & PTPRN2 & 0.037 & 2.1E-07 & 0.100 \\
\hline cg04344875 & 7 & MEST,MESTIT1 & 0.019 & 8.3E-07 & 0.179 \\
\hline cg06353830 & 1 & & -0.024 & $1.3 \mathrm{E}-06$ & 0.179 \\
\hline cg07064673 & 11 & HCCA2 & 0.016 & $1.5 \mathrm{E}-06$ & 0.179 \\
\hline cg02500300 & 4 & STOX2 & 0.014 & $2.1 \mathrm{E}-06$ & 0.204 \\
\hline cg19558802 & 15 & GLDN & 0.047 & $3.1 \mathrm{E}-06$ & 0.248 \\
\hline cg23154021 & 12 & & -0.059 & 3.7E-06 & 0.259 \\
\hline $\operatorname{cg} 14950515$ & 4 & & -0.048 & 4.5E-06 & 0.273 \\
\hline cg24393602 & 6 & GSTA4 & 0.018 & $6.3 \mathrm{E}-06$ & 0.337 \\
\hline cg06713076 & 17 & & -0.020 & 7.4E-06 & 0.354 \\
\hline cg04507925 & 2 & UNC80 & -0.030 & $9.1 \mathrm{E}-06$ & 0.354 \\
\hline cg20697519 & 1 & SLAMF8 & 0.021 & $1.0 \mathrm{E}-05$ & 0.354 \\
\hline cg03450733 & $\mathrm{X}$ & ARX & -0.061 & $1.0 \mathrm{E}-05$ & 0.354 \\
\hline $\operatorname{cg} 12948543$ & 14 & PACS2 & 0.014 & $1.2 \mathrm{E}-05$ & 0.354 \\
\hline $\operatorname{cg} 08084655$ & 17 & BTBD17 & -0.034 & $1.3 \mathrm{E}-05$ & 0.354 \\
\hline cg00152946 & 10 & & -0.017 & $1.3 \mathrm{E}-05$ & 0.354 \\
\hline cg18898267 & 8 & & -0.050 & 1.3E-05 & 0.354 \\
\hline cg20845970 & 8 & & -0.022 & 1.4E-05 & 0.354 \\
\hline cg21461300 & 13 & RASA3 & -0.038 & $1.5 \mathrm{E}-05$ & 0.354 \\
\hline cg08721112 & 1 & & -0.086 & $1.5 \mathrm{E}-05$ & 0.354 \\
\hline cg21355100 & 19 & ZNF555 & 0.024 & $1.5 \mathrm{E}-05$ & 0.354 \\
\hline cg10881110 & 1 & SLC25A34 & 0.020 & 1.7E-05 & 0.360 \\
\hline cg06534800 & 5 & DOK3 & 0.019 & 1.7E-05 & 0.360 \\
\hline cg24352317 & $X$ & LOC729609 & -0.032 & 2.1E-05 & 0.425 \\
\hline cg24757937 & 14 & SIX1 & -0.036 & 2.3E-05 & 0.425 \\
\hline cg22258713 & 8 & & 0.048 & 2.3E-05 & 0.425 \\
\hline cg24851684 & 6 & DHX16 & 0.017 & 2.4E-05 & 0.425 \\
\hline cg00893368 & 13 & RASA3 & -0.025 & $2.5 \mathrm{E}-05$ & 0.436 \\
\hline
\end{tabular}




\begin{tabular}{|llllll|}
$\operatorname{cg} 11576274$ & 1 & & -0.048 & $2.7 \mathrm{E}-05$ & 0.449 \\
$\operatorname{cg} 27590787$ & $X$ & & 0.089 & $2.9 \mathrm{E}-05$ & 0.476 \\
$\operatorname{cg} 26708559$ & 7 & MEST,MESTIT1 & 0.017 & $3.1 \mathrm{E}-05$ & 0.477 \\
$\operatorname{cg} 16204066$ & 6 & ITPR3 & -0.024 & $3.2 \mathrm{E}-05$ & 0.477 \\
\hline $\operatorname{cg} 06439589$ & X & SSR4 & 0.014 & $3.3 \mathrm{E}-05$ & 0.477 \\
$\operatorname{cg} 12905592$ & 12 & FMNL3 & 0.020 & $3.8 \mathrm{E}-05$ & 0.477 \\
$\operatorname{cg} 08772163$ & 13 & ARL11 & 0.013 & $4.1 \mathrm{E}-05$ & 0.477 \\
\hline $\operatorname{cg} 22741244$ & 2 & KLHL30 & -0.027 & $4.1 \mathrm{E}-05$ & 0.477 \\
\hline $\operatorname{cg} 11646505$ & 6 & & 0.013 & $4.2 \mathrm{E}-05$ & 0.477 \\
\hline $\operatorname{cg} 03290530$ & 3 & & 0.045 & $4.2 \mathrm{E}-05$ & 0.477 \\
\hline $\operatorname{cg} 08132116$ & 3 & NICN1 & 0.015 & $4.2 \mathrm{E}-05$ & 0.477 \\
\hline $\operatorname{cg} 21032058$ & 14 & TMEM63C & 0.012 & $4.3 \mathrm{E}-05$ & 0.477 \\
\hline $\operatorname{cg} 00329180$ & 16 & ANKRD11 & 0.020 & $4.4 \mathrm{E}-05$ & 0.477 \\
\hline $\operatorname{cg} 00044796$ & 1 & & -0.105 & $4.7 \mathrm{E}-05$ & 0.477 \\
\hline $\operatorname{cg} 13036944$ & 3 & & 0.013 & $4.7 \mathrm{E}-05$ & 0.477 \\
\hline $\operatorname{cg} 02184697$ & 16 & KREMEN2 & -0.050 & $4.8 \mathrm{E}-05$ & 0.477 \\
\hline $\operatorname{cg} 05825400$ & 17 & ABR & 0.030 & $5.0 \mathrm{E}-05$ & 0.477 \\
\hline $\operatorname{cg} 26114595$ & 17 & EFCAB5 & 0.019 & $5.0 \mathrm{E}-05$ & 0.477 \\
\hline $\operatorname{cg} 01987515$ & 2 & COPS7B & 0.010 & $5.2 \mathrm{E}-05$ & 0.477 \\
\hline $\operatorname{cg} 17733084$ & 1 & NEXN & -0.014 & $5.3 \mathrm{E}-05$ & 0.477 \\
$\operatorname{cg} 22671717$ & 1 & & -0.103 & $5.4 \mathrm{E}-05$ & 0.477 \\
$\operatorname{cg} 26289712$ & 8 & & 0.016 & $5.4 \mathrm{E}-05$ & 0.477 \\
\hline
\end{tabular}

Note: Data generated from a linear model with empirical Bayes estimation, which we used for the whole blood DNA methylation beta value comparisons between the Ranch Hand veterans with high serum TCDD levels $(n=15)$ and the control group $(n=12)$. The $q$-value was calculated using the BenjaminiHochberg method. The regression coefficient identifies the direction of methylation change between the burden groups and was determined via the model we constructed. Genes associated with each $\mathrm{CpG}$ are also given in the table. 